\title{
Training Need Analysis of the nurses working in the RDHS division Jaffna: De- velopment of a new method
}

Venoden. $D^{1}$, Kumarapeli. $V^{2}$

${ }^{1}$ International Research Fellow, Sherwood Forest Hospitals, NHS Trust, UK, ${ }^{2}$ Consultant community physician, Director, Policy, Ministry of Health

\section{Abstract}

Trainings for the nurses working in the Regional Directorate of Health Services, Jaffna wasn't conducted based on their needs as existing system to assess the needs produced no output. The objective of the study was to develop a new tool to gather and analyse the training needs of the nurses.

First stage of the project identified the strengths and weaknesses of the existing system in gathering and analysing the training needs. A new tool was developed by modifying Hennessey and Hicks training need analysis questionnaire and tested on nurses in the second stage. In the final stage, a training session was organised, based on the findings of the new tool, and effectiveness of this tool was assessed.

Appraisal system and availability of funds were identified as the major strengths while inadequate training sessions and difficulty in analysing training needs were highlighted as weaknesses of the existing system.

Response rate for testing the new tool was $71.8 \%$. Training needs existed in all five superordinate categories and varied between socio demographic and service related categories of nurses.

Nurses who were least experienced, belonged to grade 111 and working in critical units had highest need for training in all five superordinate categories.

The new tool was found to be significantly more satisfactory $(\mathrm{t}=13.780, \mathrm{df}=31, \mathrm{p}<0.001)$, and effective compared to the existing method.

In conclusion introducing the new tool to the existing appraisal system could enable gathering and analysing the training needs of the nurses effectively.

(Key words: Nurses, Training Need Analysis, Regional Directorate of Health Services, Jaffna.)

\section{Introduction}

Training, which is the enhancement of capabilities of an employee to perform his current job, is an essential component of the human resource management. (1) In contrast, development aims to improve the career, knowledge and skills for the future job of the employees. (2) Since training focuses on the current job, planning of training should focus on the current job tasks, skills and the required behaviour of the employees.

Training cycle involves Analysis, Design, Development, Implementation and Evaluation of training session, described as ADDIE model. (3) The first step of this model is Training Need Analysis (TNA), that can be done by assessing the organization goals, priorities, job tasks, required skills and the behaviour of the employees. Reflections and feedbacks of the employees in the appraisal is as well an effective tool to explore their training needs. (2)

In service training of the health staff is vital for updating their knowledge, sharpen their skills and learning from their experiences. It has brought favourable organizational and patient outcomes to National Health Services of UK. (4) Nurses, who care the patients around the clock, need regular training in order to provide quality and safe patient care. Training in the form of Continuous Professional Development (CPD) is a mandatory requirement for the Nurses in UK to renew their registration to practice; however, in developing countries CPD is often neglected. (5) 
Sri Lankan state health sector, which employed more than 32000 nurses, failed to provide regular in service trainings to majority of the nurses work in the intensive care units in 2013. $(6,7)$ Though the budgetary allocation for the basic, in service and post basic trainings of the health staff has been increased over the years, difficulties in identifying the training needs remains as a barrier to conduct trainings effectively.

Information on training needs was gathered during the appraisal, that is coupled with the annual increment process. It was however found no output on training needs have been produced based on the gathered information, hence topics for the trainings were selected in an ad hoc manner. High qualitative and incomplete information on training needs could have hindered analysing the information and producing results on training needs, though no studies in this regard had been done to prove it.

Nurses work in the Regional Directorate of Health Services (RDHS) of Jaffna suffered lack of opportunities to attend trainings due to their work load as a result of nursing shortage. Hence whatever the trainings, that they could attend, should be organized based on their training needs. This necessitated development of an effective method to assess the in-service training needs of the nurses working in the RDHS division Jaffna, which was all about this research project.

\section{Methods}

This project was carried out in three stages. In the first stage, existing system and methods of TNA was explored and identified strengths and weaknesses. Key informant interviews with the regional, hospital managers and matrons provided valuable information. Quality and quantity of the information gathered on training needs was also analysed using a check list.

In the second stage, a new method was designed to gather and analyse the training needs of the nurses based on the findings of the first stage. Hennessey Hicks training need analysis questionnaire, which was developed by University of Birmingham, licenced for online use for World Health Organization, was modified to suit for this purpose. $(8,9)$
This tool was developed in English and validated psychometrically. (8) Studies have proven that validity of this tool can be preserved even after translation in to other languages based on the specifications of the authors. (9)

This questionnaire considered both importance and performance of five major domains, named as "Superordinate categories"; Research and Audit, Communication and Teamwork, Clinical tasks, Administration and Management. Each of these superordinate categories contained many activities or tasks which nurses perform routinely. Nurses were asked to rate the importance and level of performance of each of these tasks using a Likert scale. Gaps were calculated by subtracting importance score from the performance score. Positive gap implied need for training or intervention. Tutors of the nursing colleges of Jaffna and Vavuniya and matrons of the major hospitals of Jaffna were utilized to shape up this questionnaire to suit for the local set up preserving the construct validity. All nurses work in the RDHS, Jaffna were recruited to test this new tool and they were asked to score the importance and performance of each of the tasks. Based on their scoring. gaps were calculated.

In the third stage, one day training session was organized for a selected group of the nurses and topics were selected based on the findings of the new method. At the end of the training, relevance of the topics covered in the session, in terms of fulfilling their training needs, and their satisfactory level for the existing and new method were assessed by using a questionnaire.

Ethical clearance for this study was obtained from Faculty of Medicine University of Colombo and principles of research ethics were strictly followed during entire stages of this project.

\section{Results}

Key informants identified, "Availability of funds to carry out trainings", and "Appraisal process to gather information on training needs" as the strengths of the existing system. They highlighted "Difficulty in analysing the information gathered on training needs" and "Lack of training sessions 
organized despite availability of the funds" as weaknesses.

Quantitative analysis of the training needs gathered from the appraisal revealed only $42.1 \%$ of the nurses specified their training needs, while $21.8 \%$ didn't mention anything on their training needs. The rest mentioned their development needs.

Out of 202 nurses, who were recruited for testing the new method, 145 responded with a response rate of $71.8 \%$.

\section{Socio demographics and service-related characteristics}

Among the respondents, $42.8 \%(n=62)$ were less than 30 years and another $4.7 \%(n=7)$ were above 60 years, working on contract basis. Almost 16\% $(n=23)$ of them had their permanent residence outside of the Northern Province and 15 (10.3\%) of them were Sinhalese. (Table 1)

Table 1: Selected socio-demographic characteristics of the participants $(n=145)$

\begin{tabular}{|l|l|l|}
\hline $\begin{array}{l}\text { Socio demographic } \\
\text { characteristics }\end{array}$ & $\begin{array}{l}\text { Fre- } \\
\text { quency }\end{array}$ & $\begin{array}{l}\text { Percent- } \\
\text { age }\end{array}$ \\
\hline Age category (Years) & 62 & 42.8 \\
30 or less & 43 & 29.7 \\
$31-40$ & 14 & 9.7 \\
$41-50$ & 19 & 13.1 \\
$51-60$ & 7 & 4.7 \\
Above 60 & & \\
\hline $\begin{array}{l}\text { Ethnicity } \\
\text { Sinhalese } \\
\text { Tamil }\end{array}$ & 15 & 10.3 \\
\hline $\begin{array}{l}\text { Permanent district of } \\
\text { residence }\end{array}$ & & 89.7 \\
Jaffna & 121 & 83.4 \\
$\begin{array}{l}\text { Districts of the North- } \\
\text { ern Province other } \\
\text { than Jaffna }\end{array}$ & & \\
$\begin{array}{l}\text { Districts outside the } \\
\text { Northern Province }\end{array}$ & 23 & 15.9 \\
\hline
\end{tabular}

Majority obtained basic nursing training at Nursing Training School, Jaffna ( $\mathrm{n}=121,83.4 \%$ ).

Overall, more than two third $(\mathrm{n}=97)$ were 10 or less than 10 years and one fourth were $(n=35) 2$ or less than 2 years experienced. (Table 2 )

Table 2: Selected service related characteristics of the participants $(n=145)$

\begin{tabular}{|l|l|l|}
\hline $\begin{array}{l}\text { Service related } \\
\text { characteristics }\end{array}$ & $\begin{array}{l}\text { Fre- } \\
\text { quency }\end{array}$ & $\begin{array}{l}\text { Per- } \\
\text { centage }\end{array}$ \\
\hline College of Nursing which & & \\
Jaffna & 121 & 83.4 \\
Other than Jaffna & 24 & 16.6 \\
Experience category & 35 & 24.1 \\
(years) & 62 & 42.8 \\
2 or less & 20 & 13.8 \\
3 -10 & 18 & 12.4 \\
$11-20$ & 10 & 6.9 \\
$21-30$ & 91 & 62.8 \\
31 or above & 30 & 20.6 \\
Nursing Grade & 24 & 16.6 \\
Grade 1 (Other than Sis- \\
ters and ward masters) \\
Grade 11 & 311 & \\
Grade 11 & & \\
\hline
\end{tabular}

Training needs of the nurses derived using the new method

In all five superordinate categories, means of importance scores were higher than the means of the corresponding performance scores, hence gap was positive. Highest means for the importance and performance scores were found in "communication and team work" while lowest means for importance and performance were found in "accessing and sharing information to update the knowledge" and "administrative functions" respectively. Highest mean gap was found in the "administrative function" and the lowest mean gap was found in "communication and team work". (Table 3 ) 
Table 3: Mean scores of Importance, Performance and Gap (Importance - Performance) of the superordinate categories of the participants $(n=145)$

\begin{tabular}{|l|l|l|l|}
\hline $\begin{array}{l}\text { Superordi- } \\
\text { nate catego- } \\
\text { ries }\end{array}$ & $\begin{array}{c}\text { Mean } \\
\text { score } \\
\text { for Im- } \\
\text { portance } \\
\text { (Rank) }\end{array}$ & $\begin{array}{c}\text { Mean } \\
\text { score for } \\
\text { Perfor- } \\
\text { mance } \\
\text { (Rank) }\end{array}$ & $\begin{array}{c}\text { Mean } \\
\text { score } \\
\text { for Gap } \\
\text { (Rank) }\end{array}$ \\
\hline $\begin{array}{l}\text { Accessing } \\
\text { and sharing } \\
\text { information } \\
\text { to update the } \\
\text { knowledge }\end{array}$ & $5.44(5)$ & $5.22(4)$ & $0.22(2)$ \\
\hline $\begin{array}{l}\text { Communi- } \\
\text { cation and } \\
\text { Teamwork }\end{array}$ & $5.75(1)$ & $5.59(1)$ & $0.16(5)$ \\
\hline $\begin{array}{l}\text { Medical and } \\
\text { Non-Medical } \\
\text { tasks }\end{array}$ & $5.69(2)$ & $5.47(2)$ & $0.22(2)$ \\
\hline $\begin{array}{l}\text { Administra- } \\
\text { tive functions }\end{array}$ & $5.57(4)$ & $5.21(5)$ & $0.36(1)$ \\
\hline $\begin{array}{l}\text { Personal and } \\
\text { peer manage- } \\
\text { ment }\end{array}$ & $5.64(3)$ & $5.43(3)$ & $0.21(4)$ \\
\hline Overall & 5.65 & 5.44 & 0.21 \\
\hline
\end{tabular}

Associations between the experience $(\mathrm{p}=0.001)$, grade ( $p=0.004)$ of the nurses and the mean of the overall gap were statistically significant. (Table 4) Among the years of experience groups, statistically significant associations were found between 2 or less than 2 and $11-20$ years $(p=0.026)$ and 2 or less than 2 and 21 to 30 years $(p=0.004)$.

Among the nursing grades, statistically significant association was found between grade 1 and 111 $(p=0.003)$. Table 4
Table 4: Association between Nursing College of education, experience categories, grade of Nurses and the mean of overall Gap $(n=145)$

\begin{tabular}{|c|c|c|}
\hline $\begin{array}{l}\text { Services related } \\
\text { categories of } \\
\text { the Nurses }\end{array}$ & $\begin{array}{c}\text { Mean of } \\
\text { the overall } \\
\text { Gap }\end{array}$ & $\begin{array}{l}\text { Significant } \\
\text { result (tests, } \\
\text { df and p } \\
\text { values) }\end{array}$ \\
\hline \multicolumn{2}{|c|}{$\begin{array}{l}\text { Nursing College of } \\
\text { education }\end{array}$} & $t=-1.062$ \\
\hline Jaffna & 0.18 & $\mathrm{df}=143$ \\
\hline $\begin{array}{l}\text { Other than } \\
\text { Jaffna }\end{array}$ & 0.36 & $p=0.29$ \\
\hline \multicolumn{3}{|c|}{ Experience category (years) } \\
\hline 2 or less than 2 & 0.53 & $F=4.804$ \\
\hline $3-10$ & 0.30 & $\mathrm{df}=144$ \\
\hline $11-20$ & -0.07 & $\mathrm{p}=0.001$ \\
\hline $21-30$ & -0.22 & \\
\hline \multicolumn{3}{|l|}{31 or above } \\
\hline \multicolumn{3}{|c|}{ Grade of the Nurses } \\
\hline Grade 1 & -0.15 & $F=5.792$ \\
\hline Grade 11 & 0.12 & $\mathrm{df}=144$ \\
\hline Grade 111 & 0.36 & $\mathrm{p}=0.004$ \\
\hline
\end{tabular}

Associations between work units and mean of overall gap was statistically significant $(\mathrm{p}=0.002)$. (Table 5) Among the working units, statistically significant associations were found between wards group and the group of intensive care unit, operation theatre, blood bank, oncology units $(\mathrm{p}=0.002)$ and the group of intensive care unit, operation theatre, blood bank, oncology units and the group of outpatient department, clinic, emergency treatment unit, preliminary care units $(\mathrm{p}=0.012)$.

Nurses working in the intensive care unit, operation theatre, blood bank, and oncology units had highest means of gaps in all superordinate categories. 
Table 5: Association between Type of hospitals, work units and the means of the overall Gaps $(n=145)$

\begin{tabular}{|l|l|l|}
\hline $\begin{array}{l}\text { Services relat- } \\
\text { ed categories }\end{array}$ & $\begin{array}{l}\text { Mean of } \\
\text { the over- }\end{array}$ & Significant \\
of the Nurses & all Gap & and p values) \\
\hline \multicolumn{2}{|l|}{ Type of the Hospitals } \\
\hline Type A BH & 0.27 & $\mathrm{~F}=1.374$ \\
\hline Type B BH & 0.26 & $\mathrm{df}=144$ \\
\hline DH & 0.01 & $\mathrm{p}=0.256$ \\
\hline Working Units & 0.11 & $\mathrm{~F}=6.631$ \\
\hline Wards & 0.66 & $\mathrm{df}=144$ \\
\hline $\begin{array}{l}\text { ICU OT, BB, } \\
\text { Oncology }\end{array}$ & & $\mathrm{p}=0.002$ \\
\hline $\begin{array}{l}\text { OPD, Clinic, } \\
\text { ETU, PCU }\end{array}$ & 0.08 & \\
\hline
\end{tabular}

Training topics for the training were selected based on the superordinate categories, which had the highest mean of gap (Administrative functions), highest mean of importance (Communication and Teamwork and Medical and non-medical tasks) and lowest mean of performance. Trainees were selected based on the service related category/ categories, which had the highest means of overall and superordinate categories gaps.

\section{Assessing effectiveness of the new method}

Out of 41 participants, who were invited for the in service training, 39 presented for the training. Among them, 32 have participated for testing of the new method. Those 32 were recruited for assessing the effectiveness of the new method. Their rating on level of satisfaction between the existing and new methods was statistically significant.

$(t=13.780, d f=31, p<0.001)$. All of them rated the topics covered in the training was relevant to their training needs.

\section{Discussion}

The appraisal system coupled with annual increment was identified as a strength by the key informants to determine the training needs; however, the tool used to gather the data on training needs raised the concern. Though a development officer, who was a Graduate, was designated to do this job for the nurses, highly qualitative and incomplete data gathered on training needs hindered her to produce useful output. Similar findings were obtained in an international study done on "Problems of clinical nurses' performance appraisal system". (10)

The new tool was designed to ensure gathering specific data on training needs instead of a mixture of training and development needs as like the existing one. As each question of the new tool specify a task or activity carried out by nurses, and all questions were grouped under five superordinate categories, organization, and analysis of the data gathered using this tool became easier. Analysis, using Microsoft Excel and SPSS, could provide more deep insight on association of training needs among various socio-demographic and service related categories of the nurses.

During the 26 years of civil unrest, which came to an end in 2009, RDHS division Jaffna suffered from severe shortage of all categories of health staff and the worst one was shortage for the nurses. Since then nursing shortages and new demand for the nurses were gradually being addressed by appointing junior nurses, just after completion of their basic training and contracting retired nurses. This explained the socio demographics and service related characteristics of nurses; predominantly junior, and least experienced along with a population of nurses over 60 years.

As most of the nurses were less experienced, the gaps of all super ordinate categories were positive, which meant that performance of all superordinate categories were less compared to importance; also, it could be the reason for the highest gap found in administration among nurses as most of them were belonged to grade 111. The current trend of the state health sector in improving quality and safety of patient care, through developing 
effective communication and team work, could have resulted in reducing the gap in communication and team work among the nurses. $(11,12)$ These findings were comparable to the results of an Ethiopian study on "Factors affecting Performance of the Nurses", that revealed almost half of the participants were less than 2 years of experienced and their performance was good in interpersonal communication while poor in supervision, which is an administrative function. (13)

The finding of junior nurses had highest mean for overall gap, was alike the finding of a study done on "Identifying the factors influencing the performance of Nurses". (14) In addition. results of our study revealed junior nurses had highest gaps in all five superordinate categories.

Nurses work in the intensive care unit, operation theatre, blood bank, and oncology units had highest means of gaps in all superordinate categories, as junior nurses were mostly placed in those units.

The gap between the importance and performance could be due to lack of training or working conditions or both; hence careful assessment should be done prior to plan and implement an intervention. $(8,15)$ The predominant reason for the gap observed in this project was lack of training as majority of the nurses were less experienced and not undergone any need based trainings.

Means of importance of all 5 superordinate categories were above 5, which implied nurses identified all these categories were more important. Similarly, all the performance means were above 5 which meant, nurses performed reasonably well to match the expectations. Hence, it sounded rational to select topics not only based on the size of gaps, but also the level of importance and performance. Therefore, superordinate categories had highest means for importance and gaps, and lowest mean for performance were selected for training. Junior nurses were given higher priority for the training session as they had highest gaps in all superordinate categories.

The new tool was effective in picking up the training needs since training topics selected based

-14 - on using this tool was identified as their training needs by the nurses who attended to the training. Further the observation of statistically significant means of satisfaction of the nurses towards new (3.44) and existing (1.69) methods implied the new method was user friendly.

\section{Conclusion}

Existing method of TNA of the nurses was only limited to gathering of the information on training needs, which was not specific, incomplete and not user friendly. New tool introduced to pick up the training needs of the nurses was found to be effective. Hence it is recommended to introduce the new tool to the existing appraisal system to pick up and analyse the training needs.

\section{Acknowledgement}

I am so pleased and privileged to thank, Dr.Vindya Kumarapeli, Consultant Community Physician, and Director, Policy, Ministry of Health, for the intellectual contribution and guidance; Dr.K.Nanthakumaran, Former RDHS, Jaffna, and Director, DGH Vavuniya for the support and authority provided by him to carry out this project in the RDHS division Jaffna

All the participants of the KII for their valuable contribution to prepare the new TNA tool

Mrs.Sangeetha Kopinath, Development Officer, RDHS office for her valuable support in gathering and summarizing data on training needs from the existing appraisal system; all the participants of this project for their valuable contribution in evaluating the new TNA tool; Medical Superintends of the Base Hospitals and District Medical Officers of the Divisional Hospitals and Matrons or Hospital In charge Nursing Officers for their support in gathering data; participants of the training, for their enthusiastic contribution in the evaluation of the new tool and all others including my family members for their support.

\section{Conflict of interest}

I, the principal author of this this research project, wish to assure that there are no conflict of interests according to my knowledge and conscience

Jaffna Medical Journal 


\section{Reference}

1. Shumannm PL. Training \& Development. Available online at http://www.slideshare.net/ dennimardomingo/training-cycle-38419535/ [accessed on 17 January 2017]

2. Decanzo DA, Robbins SP. Fundamentals of Human Resource Management, 10th ed. USA: John Wiley \& Sons, Inc; 2010.

3. Desssler G. Fundamentals of Human Resource Management, 3rd ed. Edinburgh: Pearson New International Edition; 2014.

4. West M, Dawson J, Admasachew L, Topakas A. NHS Staff Management and Health Service Quality. Available online at https://www.gov. uk/government/uploads/system/uploads/ attachment/ [accessed on 27 December 2016].

5. Royal College of Nursing. Continuing Professional Development (CPD) for nurses working in the United Kingdom (UK). Available online at https://my.rcn.org.uk/ data/assets/pdf_file/0006/583260/16.14 RCN_Factsheet_Continuing_Professional_ Development_for_nurses_working_in_the UK.pdf [accessed on 3 November 2016].

6. Health Information Unit. Human Resource Profile. Colombo: Ministry of Health; 2015.

7. National Intensive Care Surveillance. Critical care bed system for Sri Lanka. Colombo: Ministry of Health; 2013.

8. Hennessy DA, Hicks CM. Hennessy-Hicks Training Needs Analysis Questionnaire and Manual. Available online at http://www.who. int/workforcealliance/knowledge/toolkit/19. pdf?ua=1 [accessed on 2 October 2015].

9. Markakir A, Antonakis N, Hicks CM, Lionis C. Translating and validating a Training Needs Assessment tool into Greek. BMC Health Services Research 2007; 7(65):Available online at https://bmchealthservres. biomedcentral com/articles/10.1186/1472-6963-7-65 [accessed on 26 February 2017].
10. Nikpeyma IN, Saeedi IZA, Azargashb E, Majd HA. Problems of Clinical Nurse Performance Appraisal System: A Qualitative Study. Asian Nursing Research 2014; 15(22): Available online at http://www.sciencedirect.com/ science/article/pii/S1976131713000650 [accessed on 14 March 2017]

11. Directorate of Healthcare Quality and Safety. Manual for Master Trainers Healthcare Quality and Safety. Colombo Ministry of Health: Ministry of Health; 2015.

12. Gluyas H. Effective communication and Team work promote Patient Safety. Nursing Standard 2015; 29(49): Available online at http://journals.rcni.com/doi/pdfplus/10.7748/ ns.29.49.50.e10042 [accessed on 2 May 2017].

13. Tesfaye T, Abera A, Balcha F, Nemera G, Belina S. Assessment of Factors Affecting Performance of Nurses Working at Jimma University Specialized Hospital in Jimma Town, Oromia Region, South-West Ethiopia. Journal of Nursing and Care 2015; 4(312): Available online at https://www.omicsgroup. org/journals/assessment-of-factors-affectingperformance-of-nurses-working-atjimmauniversity-specialized-hospital-in-jimmatown-oromia-regions-2167-1168-1000312. php?aid=65245 [accessed on 26 January 2017]

14. Al Ahmadi $\mathrm{H}$. Factors affecting performance of hospital nurses in Riyadh Region, Saudi Arabia. International Journal of Health Care Quality Assurance 2009;22(1): Available online at Avhttp://www.emeraldinsight.com/doi/ abs/10.1108/09526860910927943 [accessed on 23 April 2017]

15. Mayer B. Tips for Improving Nurse Performance. Available online at http://www. healthleadersmedia.com/nurse-leaders/tipsimproving-nurse-performance [accessed on 23 March 2017]. 